\title{
Oncological Outcomes and Morbidity of Radical Cystectomy for Bladder Cancer: Experience of a Senegalese Centre
}

\author{
Aboubacar Traore ${ }^{1, *}$, Cyrille Ze Ondo ${ }^{2}$, Alioune Sarr ${ }^{2}$, Babacar Sine $^{2}$, Modou Ndiaye ${ }^{2}$, \\ Abdoulaye Ndiath ${ }^{2}$, Yaya Sow ${ }^{3}$, Boubacar Fall ${ }^{1}$, Babacar Diao ${ }^{2}$, Pape Ameth Fall ${ }^{2}$, \\ Alain Khassim Ndoye ${ }^{2}$, Mamadou Ba ${ }^{2}$ \\ ${ }^{1}$ Urology-Andrology Department, De la Paix Hospital, Ziguinchor, Senegal \\ ${ }^{2}$ Urology-Andrology Department, Aristide Le-Dantec Hospital, Dakar, Senegal \\ ${ }^{3}$ Urology-Andrology Department, Regional Hospital, Saint Louis, Senegal
}

Email address:

traboubacar88@yahoo.fr (A. Traore)

${ }^{*}$ Corresponding author

\section{To cite this article:}

Aboubacar Traore, Cyrille Ze Ondo, Alioune Sarr, Babacar Sine, Modou Ndiaye, Abdoulaye Ndiath, Yaya Sow, Boubacar Fall, Babacar Diao, Pape Ameth Fall, Alain Khassim Ndoye, Mamadou Ba. Oncological Outcomes and Morbidity of Radical Cystectomy for Bladder Cancer: Experience of a Senegalese Centre. International Journal of Clinical Urology. Vol. 4, No. 1, 2020, pp. 17-20. doi: $10.11648 /$ j.ijcu. 20200401.14

Received: February 5, 2020; Accepted: February 28, 2020; Published: March 10, 2020

\begin{abstract}
The purpose of this paperwork is to assess the oncological findings and the morbidity rate after complete cystectomy in our department. Patients and methods: We conducted a backward and descriptive study during a 80-monthperiod range from September 2011 to May 2018, in the Urology Department of Aristide Le Dantec Teaching Hospital standing as a referral structure in our country (Senegal). Results: Nineteen patients were included accounting for 13 men and 6 women corresponding to a sex ratio of 2. The mean age was at 58 years old (extremes range from 32 to 77 years old). Radical cystectomy consisted of an anterior pelvectomy and transileal cutaneous ureterostomy by Bricker approach in 6 women, a radical cystoprostatectomy with transileal cutaneous ureterostomy by Bricker approach in 12 men and a radical cystoprostatectomy followed by Studer orthotopic neobladder in 1 patient. Early post-operative morbidity consisted of one case of parietal suppuration (grade I), two cases of evisceration (grade IIIb), one case of digestive fistula (grade IIIb), and uroperitoneal peritonitis (grade IIIb) secondary to suture loosening of the uretero-ileal anastomosis (which occurred in the patient who had Studer neobladder). This patient died in resuscitation ward after surgical repair of the uretero-iliary anastomosis. Late complications were a case of acute pyelonephritis three months after cystectomy and a case of flanged occlusion. Two patients with urothelial carcinoma had received adjuvant chemotherapy using the M-VAC protocol. After an average follow-up of 15 months we recorded 13 deaths, three patients were lost of sight and three others respectively lived 4 years and 2 months, 5years and 8 months and 6years and 8 months after radical cystectomy. Mean overall survival was 15 months ( 4.2 to 25.8 months) with a median survival of 6 months. The only patient who had Studer neobladder died one week after cystectomy. The mean overall survival after previous pelvectomy was 17.2 months and that after cystoprostatectomy was 15.18 months. Conclusion: This work highlights the very poor prognosis of bladder cancers in our context linked to the advanced stage of tumours at the time of diagnosis, the rarity of endoscopic equipment essential for the diagnosis, treatment and monitoring of bladder cancers, the frequency of radiochemically resistant squamous cell carcinoma, the unavailability of chemotherapy in urothelial carcinoma to enable multimodal treatment, and the heaviness and complexity of radical cystectomy.
\end{abstract}

Keywords: Bladder Cancer, Cystectomy, Morbidity, Oncological Outcomes 


\section{Introduction}

Bladder cancer is the 7th most prevalent malignancy worldwide and mostly occurs after 60 years of age [1]. In our context, this condition is the $2^{\text {nd }}$ type of cancer after prostate cancer and is followed by kidney cancer [2]. Its outcome is poor due to a late diagnosis. The core therapy of bladder cancers with muscle invasion relies on radical cystectomy. This a heavy surgical approach known by its mutilant character and its high immediate and long-term postoperative fatality.

The purpose of this paperwork is to assess the oncological findings and the morbidity rate after complete cystectomy in our department.

\section{Patients and Methods}

We conducted a backward and descriptive study during a 80-month-period range from September 2011 to May 2018, in the Urology Department of Aristide Le Dantec Teaching Hospital standing as a referral structure in our country (Senegal). We included patients undergoing a bladder cancer and treated by radical cystectomy regardless of the type of urine derivation. Were excluded all patients with bladder cancer on whom surgery was not performed or who only had a urine derivation. The general appearance of patients were assessed by using the American Society of Anesthesia Score (ASA) and the clinical stage according to TNM classification 2009 set by the UICC. Post-operative complications are staged according to Clavien-Dindo classification. Microsoft Excel 2013 Software helped analyse our findings.

\section{Results}

Nineteen patients were included accounting for 13 men and 6 women corresponding to a sex ratio of 2 . The mean age was at 58 years old (extremes range from 32 to 77 years old). The most affected age group was between 60 to 80 years old. Ten patients had a history of freshwater swimming in bilharzia endemic area. Four of them were smokers with packet-years ranging from 7 to 10 . Unlike, 7 patients didn't have a known risk factor. All patients presented a hematuria (terminal or total), associated with lower urinary tract symptoms in 13 patients. The mean consultation time-limit was 6 months (extremes range from 3 months to 1 year). One patient was staged ASA I, 14 ASA II and 4 ASA III.

The histological pattern was an urothelial carcinoma for 14 patients, an epidermoid carcinoma for 4 patients and 1 case of adenocarcinoma. For all patients, it was an invasive cancer.

The cancer was restricted to the bladder in 16 cases while it spreaded in 3 patients ( 2 cases of pulmonary metastasis and a case of hepatic metastasis).

Radical cystectomy consisted of an anterior pelvectomy and transileal cutaneous ureterostomy by Bricker approach in 6 women, a radical cystoprostatectomy with transileal cutaneous ureterostomy by Bricker approach in 12 men and a radical cystoprostatectomy followed by Studer orthotopic neobladder in 1 patient. A standard ilio-occlusive lymph node curage was performed in all patients.

We didn't outline neither accidents nor incidents during surgery. No peroperative death were recorded.

The histological examination of the specimen found healthy edges for all patients. Lymph node curage didn't point out lymph node invasion and the number of taken away lymph nodes was at average 6 (extremes 4 and 10).

The average length of hospitalization was 17 days ( 8 to 30 days). Early post-operative morbidity consisted of one case of parietal suppuration (grade I), two cases of evisceration (grade IIIb), one case of digestive fistula (grade IIIb), and uroperitoneal peritonitis (grade IIIb) secondary to suture loosening of the uretero-ileal anastomosis (which occurred in the patient who had Studer neobladder). This patient died in resuscitation ward after surgical repair of the uretero-iliary anastomosis. Late complications were a case of acute pyelonephritis three months after cystectomy and a case of flanged occlusion.

Two patients with urothelial carcinoma had received adjuvant chemotherapy using the M-VAC protocol. The patient classified pT2bN2M0 underwent 2 sessions while the one who was classified pT4N0M went for 1 session. After an average follow-up of 15 months we recorded 13 deaths, three patients were lost of sight and three others respectively lived 4 years and 2 months, 5years and 8 months and 6years and 8 months after radical cystectomy (Figure 1). Mean overall survival was 15 months (4.2 to 25.8 months) with a median survival of 6 months. The only patient who had Studer neobladder died one week after cystectomy. The mean overall survival after previous pelvectomy was 17.2 months and that after cystoprostatectomy was 15.18 months.

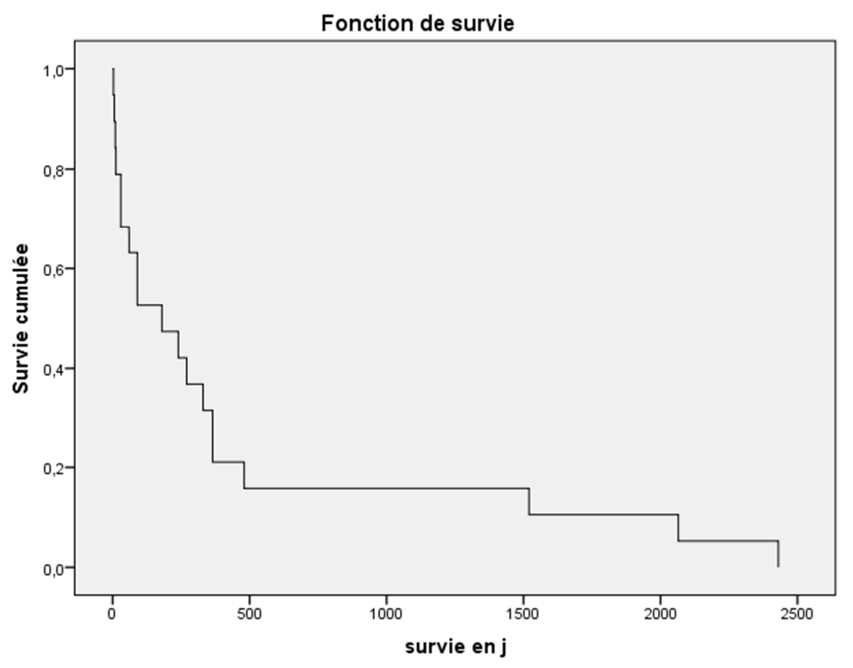

Figure 1. Global Survival Curve.

\section{Discussion}

The male predominance of bladder cancer in this series has already been reported in several studies in Africa [2] as well as in Europe [3]. This may be explained by increased 
exposure to tobacco and bilharzia, which are the main risk factors. The average age of the patients was 58 years. In Algeria and France, the mean age of patients was much higher, 64.2 [4] and 65 years [5] respectively. This relatively young age of our patients can be explained by early exposure to the main etiologic factor in our context which is urogenital bilharzia. End stage or total macroscopic hematuria was the main revealing sign of bladder tumor. This was similar to the series reported by Diao et al. where $88 \%$ of patients had hematuria. There is a link between ASA score and postoperative morbidity. Morbidity increases significantly when the ASA score is greater than or equal to 3, as the risk of gastrointestinal fistula increases from $2.8 \%$ for an ASA score of 1 or 2 to $15 \%$ when the score is greater than or equal to 3 [6]. In our series four patients had an ASA score greater than or equal to 3

The risk of developing bladder cancer is 2 to 4 times higher in smokers compared to non-smokers and this risk increases with the intensity and/or duration of smoking [7]. In our series four patients $(21 \%)$ were active smokers due to 7 to 15 pack-years of smoking. Urinary bilharzia is a risk factor for squamous cell carcinoma of the bladder which has a very high prevalence in Africa. The frequency of this histological type is increasing in countries where bilharzia is endemic (East Africa and the Middle East) where it accounts for $66-77 \%$ of bladder tumours [8]. We found a notion of freshwater swimming in a bilharzia endemic zone in ten patients $(52.63 \%)$, four of whom were active smokers. In Africa the high frequency of squamous cell carcinoma in endemic areas of urinary bilharzia as in Egypt has been reported in several studies [9]. In Senegal, Diao et al. showed in a 2008 study that squamous cell carcinoma accounted for $50.7 \%$ of cases. In our series, urothelial carcinoma was the predominant histological type with $64.7 \%$ of cases compared to $21 \%$ for squamous cell carcinoma. The decline in the prevalence of squamous cell carcinoma in Senegal can probably be explained by the implementation of the national programme to fight bilharziasis since 1988 by the country's health authorities.

Bricker trans-ileal cutaneous ureterostomy urinary diversion was performed in 18 patients after total cystectomy and Studer bladder replacement in one patient. Bricker approach is the referrential urinary derivation after cystectomy. Our choice of this shunt is guided by the large tumour volume, the damage to the bladder trigone and the absence of extemporaneous examination in our context. In regards of early morbidity, parietal suppuration (Grade I) was observed in one patient. The frequencies of parietal suppuration reported in the literature vary between 2 and $20 \%$ [10]. Parietal suppuration is a source of prolonged hospitalisation and can be life-threatening with the occurrence of septicaemia. Evisceration (Grade IIIb) occurred in two patients in our study and required surgical reintervention. Digestive fistula (Grade IIIb) is a major complication, reported by Malavaud in $2.5 \%$ of cases [6]. It was observed in one patient in our study and required surgical re-intervention. Its prevention mainly consists of the use of a segment of non-irradiated small intestine and the most rigorous surgical technique possible [11]. Uroperitoneal peritonitis (Grade IIIb) had occurred in a patient after Studer neobladder. It was secondary to a suture rupture of the uretero-iliac anastomosis and required re-intervention followed by the death of the patient a few hours later. Studer et al. reported three cases of postoperative peritonitis in a series of 100 patients (3\%) [12], while Benchekroun [13] found two cases (out of a series of 225 patients) of peritonitis due to suture loosening of the digestive anastomosis.

The late morbidity was a type of acute pyelonephritis in one patient. This is a complication that can lead to long-term impairment of renal function. It is reported in $1.5 \%$ to $21.2 \%$ of cases in the literature. The most common cause is ileoureteral reflux. A bowel clamp occlusion occurred in one patient 11 months after cystectomy. The frequency of postoperative hail occlusions varies between $1.8 \%$ and $23.6 \%$ in the literature [14].

Since the 1990s, it has been accepted that the overall and specific 5-year survival rates for patients with radical cystectomy (all stages) were between $50-60 \%$ and $60-70 \%$ respectively. This survival is highly related to the anatomopathological pattern. Frazier [15] reported a 5year survival of $39 \%$ in patients with non-localized tumors with a poor prognosis. In contrast, for tumours localized to the bladder and not extending beyond the muscle, the chances of overall survival at 5 years are greater than $80 \%$ (nearly $90 \%$ for specific survival). In our series, only three patients were alive after an average follow-up of 15 months after radical cystectomy. This poor survival is related to the advanced stage of the cancers, the frequency of squamous cell carcinoma may be sensitive to complementary treatments and the non-use in some cases of neo-adjuvant chemotherapy.

\section{Conclusion}

This work highlights the very poor prognosis of bladder cancers in our context linked to the advanced stage of tumours at the time of diagnosis, the rarity of endoscopic equipment essential for the diagnosis, treatment and monitoring of bladder cancers, the frequency of radiochemically resistant squamous cell carcinoma, the unavailability of chemotherapy in urothelial carcinoma to enable multimodal treatment, and the heaviness and complexity of radical cystectomy. Raising public awareness of risk factors and consultation time, the improvement of facilities and both medical and paramedical training in the treatment of this cancer should be necessarily taken into account (among many others) to better patient prognosis.

\section{Conflict of Interest Statement}

All the authors do not have any possible conflicts of interest. 


\section{References}

[1] Rouprêt M, Neuzillet Y, Masson-Lecomte A. et al. Recommandations en onco-urologie 2016-2018 du CCAFU: Tumeurs de la vessie Prog Urol 2016; 27: Suppl. 1 S67-S92.

[2] Diao B, Thiam A, Fall B, et al. Les cancers de vessie au Sénégal: particularités Épidémiologiques, cliniques et histologiques. Prog Urol 2008; 18: 445-558.

[3] Boucher A. Anatomie topographique descriptive et fonctionnelle; Tome 4. L'abdomen, la région rétro-péritonéale, le petit bassin, le périnée, 1991.

[4] . Benoit G, Giuiliano F. Anatomie chirurgicale et voies d'abords de la vessie -Editions techniques. EMC techniques chirurgicales -urologie-gynécologie. 41160, 1991, 9p.

[5] Dandekar NP, Tonggaonkar HB, Dalal AV, et al. Partial cystectomy for invasive bladder cancer. J Surg Oncol 1995; 60 (1): 24-29.

[6] Malavaud B. Complications for Radical Cystectomy. Impact of the American Society of Anesthesiologists Score. Eur Urol 2001; 39: 79-84.

[7] Cherif M, Chakroun M, Bouzouita A, et al. Caractéristiques épidémiologiques du cancer de la vessie chez la femme en Tunisie. Afr J Urol 2016; 22: 71-75.

[8] Mitropoulos D, Artibani W, Graefen M, Remzi M, Rouprêt M, Truss M. Reporting and grading of complications after urologic surgical procedures: an ad hoc EAU guidelines panel assessment and recommendations. Eur Urol 2012; 61: 341349 .

[9] Irani J. Tumeurs urothéliales: épidémiologie du cancer de vessie. Prog Urol 2003; 13: 1207-1208.

[10] Botto H. Remplacement de vessie après cystectomie radicale pour cancer: expérience de l'hôpital Foch. Mémoires de l'Académie Nationale de Chirurgie 2003; 2 (4): 14-19.

[11] Lebret T, Herve JM, Lugagne PM, et al. Incidence et prise en charge des complications non urologiques après cystectomie pour cancer. Congrès de l'association française de l'urologie AFU 2001 (référence incomplète).

[12] Zerbib M, Slama J, Bouchot O. Les dérivations urinaires, techniques chirurgicales $2^{\text {ème }}$ partie. Prog Urol 2002; 12: 874890.

[13] Benchekroun A, El Alj HA, Essayegh H, et al. Tumeurs infiltrantes de vessie: étude rétrospective à propos de 225 cas. Ann Urol 2003; 37: 279-28.

[14] Lebret T, Hervé JM, Yonneau L, et al. Etude de la survie après cystectomie pour cancer de vessie. A propos de 504 cas. Prog Urol 2000; 10: 553-560.

[15] Frazier HA, Robertson JE, Dodger RK et al. The value of pathologic factors in predicting cancer-specific survival among patients treated with radical cystectomy for transitional cell carcinoma of the bladder and prostate. Cancer 1993 jun 15; 71 (12): 3993-4001. 